Check for updates

The BMJ

Cite this as: $B M J 2022 ; 376: 0269$ http://dx.doi.org/10.1136/bmj.0269 Published: 01 February 2022

\title{
Covid-19: Government abandons mandatory vaccination of NHS staff
}

\section{Gareth lacobucci}

The government has done a last minute U turn on its plan to make covid-19 vaccination mandatory for NHS staff in England.

Medical bodies welcomed the reversal on the plan, which they had warned would exacerbate chronic workforce shortages in the health service by causing thousands of staff to lose their jobs. ${ }^{12}$

Announcing the decision on 31 January, ${ }^{3}$ England's health and social care secretary, Sajid Javid, said that the balance of opportunities and risks of the policy had shifted with the dominance of the omicron variant, with the population being as a whole better protected against the need for hospital admission, and with omicron being "intrinsically less severe" than delta.

"While vaccination remains our very best line of defence, I believe it is no longer proportionate to require vaccination as a condition of deployment by statute," Javid told MPs.

The decision came just three days before the 3 February deadline given to unvaccinated staff who deal directly with patients to have had their first dose or risk losing their job. The government said that more than 127 ooo NHS staff had come forward for a vaccine dose since it first consulted on the issue in September. But on 16 January 80092 staff (5.4\% of the total) still remained unvaccinated.

Javid said the regulations would now be revoked, subject to public consultation and parliamentary approval. He will also remove vaccination as a condition of working in care homes, a policy that had been in place since last year and was estimated to have resulted in 40 ooo staff leaving their posts in the sector.

Chaand Nagpaul, BMA council chair, said, "While the BMA fully supports the vaccination rollout, it is now clear that the impact of mandatory vaccination on NHS staffing levels at a time of acute workforce shortages and record waiting lists would have put the continuity of healthcare services at risk and therefore compromised patient care and safety. Therefore, today's decision is the right one and is a more proportionate approach that takes into account the changing nature of covid-19."

Andrew Goddard, president of the Royal College of Physicians, said, "We continue to strongly encourage all our members to take up the offer of covid-19 and flu vaccinations as the benefits to both them and their patients are clear, but we also believe it is important that this remains a free choice.

"Removing the need for mandatory vaccinations would reduce the risk to patient care that we will undoubtedly see if we lose more staff, and it will improve our ability to respond to urgent and emergency care pressures as well as the backlog created by covid."

In a joint statement the chief executives of the NHS Confederation, Matthew Taylor, and NHS Providers, Chris Hopson, said, "NHS leaders are frustrated to have such a significant change in policy at the 11th hour, given all the hard and complex work that has gone into meeting the deadline set by the government. They recognise the reasons ... but there will be concern at what this means for wider messaging about the importance of vaccination for the population as a whole."

Rachel Harrison, national officer for the GMB union said, “The government's U turn comes too late in the day for thousands of workers in our care homes who have already lost their jobs because of an unrealistic vaccination policy."

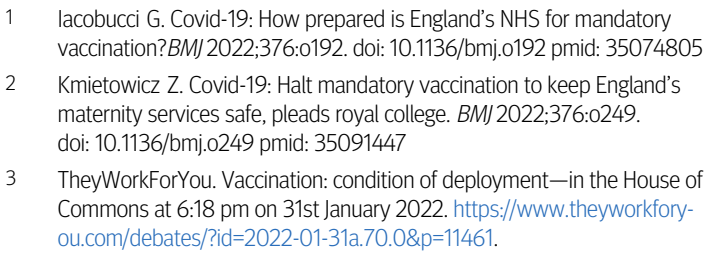
vaccination?BMJ 2022;376:0192. doi: 10.1136/bmj.0192 pmid: 35074805

2 Kmietowicz Z. Covid-19: Halt mandatory vaccination to keep England's maternity services safe, pleads royal college. BMJ2022;376:0249. doi: 10.1136/bmi.0249 pmid: 35091447

3 TheyWorkForYou. Vaccination: condition of deployment-in the House of Commons at 6:18 pm on 31st January 2022. https://www.theyworkforyou.com/debates/?id=2022-01-31a.70.0\&p=11461.

This article is made freely available for personal use in accordance with BMJ's website terms and conditions for the duration of the covid-19 pandemic or until otherwise determined by BMJ. You may download and print the article for any lawful, non-commercial purpose (including text and data mining) provided that all copyright notices and trade marks are retained. 